\title{
Journal of Cardiology and Therapy
}

\section{Validation of Type A Behaviour Questionnaire in Relation to Social Class and Coronary Artery Disease: The Indian Rating Scale for Type A Behaviour}

\author{
Agnieszka Wilczynska, Ram B Singh, Jan Fedacko, Shantanu Singhal, Neelesh Gupta, Charu Gangwar
}

Agnieszka Wilczynska, Krakow University, Krakow, Poland Ram B Singh, Halberg Hospital and Research Institute, Moradabad, India

Jan Fedacko, PJ Safaric University, Kosice, Slovakia

Shantanu Singhal, Department of Medicine, Amrata Institute of Medical Sciences, Kochi (Kerala), India

Neelesh Gupta, University of South Alabama Medical Center, Mobile AL USA

Charu Gangwar, Research Scholar, IFTM University, Moradabad and Pollution Ecology Research Lab, Hindu College, Moradabad, India

Conflict-of-interest statement: The author(s) declare(s) that there is no conflict of interest regarding the publication of this paper.

Open-Access: This article is an open-access article which was selected by an in-house editor and fully peer-reviewed by external reviewers. It is distributed in accordance with the Creative Commons Attribution Non Commercial (CC BY-NC 4.0) license, which permits others to distribute, remix, adapt, build upon this work noncommercially, and license their derivative works on different terms, provided the original work is properly cited and the use is noncommercial. See: http://creativecommons.org/licenses/by-nc/4.0/

Correspondence to: Ram B Singh, MD, FICN, Halberg Hospital and Research Institute, Moradabad - 10 (UP), 244001, India.

Email: rbs@tsimtsoum.net

Telephone: +91-9997794102

Received: November 20, 2017

Revised: January 28, 2018

Accepted: January 31, 2018

Published online: February 2, 2018

\section{ABSTRACT}

This study was conducted to validate the questionnaire for assessment of type A behaviour and to determine its relation with socioeconomic status and coronary artery disease (CAD) in a randomly selected urban population. We studied 1806 subjects (904 men and 902 women) aged 25-64 years. The survey instruments were questionnaire: modified from existing questionnaires (Likeret scale, Jenkins activity survey and Friedman and Rosenman structured interview questionnaires). The questionnaire for assessment of type A behaviour was administered by a psychologist and subjects were divided into type A behaviour $(n=306)$, possible type A behaviour ( $n=157)$ or no such behaviour ( $n=1343)$ according to rating of their type A behaviour based on scores of various attributes such as hostility, aggressiveness, ambitiousness, competitiveness and pace or time urgency. The prevalence of type A behaviour was significantly greater among men compared to women $(21.9 v s 11.9 \%, p<0.01)$. The overall prevalence of type A and possible type A behavior was also significantly higher in men than women $(32.4 v s 18.8 \%, p<0.01)$ and the overall prevalence of total behaviour abnormality was $25.6 \%$ in both sexes. Type A behaviour was highly prevalent among social class 1 and 2 subjects in both sexes and showed significant association with CAD. The findings indicate that type A behaviour assessed by scores constructed based on various attributes of behaviour is accurate and the personality rating scale validated by us may be used successfully in other population groups of India. The novelity is that these parameters in conjunction with other cultural factors can be used for rating of behavior in other populations of Asia and Europe because of cultural differences in Europe, Asia and North America.

Key words: Personality; Behaviour; Social class; Coronary artery Disease; Hostility

(C) 2018 The Author(s). Published by ACT Publishing Group Ltd. All rights reserved.

Wilczynska A, Singh RB, Fedacko J, Singhal S, Gupta N, Gangwar C. Validation of Type A Behaviour Questionnaire in Relation to Social Class and Coronary Artery Disease: The Indian Rating Scale for Type A Behaviour. Journal of Cardiology and Therapy 2018; 5(1): 707-712 Available from: URL: http://www.ghrnet.org/index.php/jct/ article/view/2193

\section{INTRODUCTION}

WHO study group and Indian consensus group have suggested that 
changes in diet and lifestyle factors due to economic development and urbanization appear to be important in the pathogenesis of cardiovascular disease (CVD) and diabetes in most countries ${ }^{[1,2]}$. People of south Asian origin living in developed countries and urban populations of India have an increased susceptibility to coronary artery disease (CAD) which is not explained by conventional risk factors $^{[1-5]}$. In developed countries, type A behaviour, depression, anxiety and stress have been demonstrated to be important risk factors of CADS-10. However, no study has examined the association of these risk factors with CAD in Indians which may explain the cause of increased risk of CAD. Recent studies indicate that hostility is the most important determinant of $\mathrm{CAD}^{[5-8]}$. Hostility is a more serious type of aggression in which patient wish to harm others which has connotations of anger, aggression and a chronic negative outlook. It is a component of type A behavior ${ }^{[9-10]}$, which is also characterized with competitiveness, ambitiousness, pace and aggressiveness without a wish to oppose and harm others. No previously validated Indian criteria for assessment of various component of type A behaviour exist and no population based study has examined the association of type A behaviour with CAD. In view of the differences in culture and differences in diet and lifestyle, the clinical characteristics and method of presentation of type A behaviour may differ in various population groups. Hence, finding out a modified questionnaire for assessment of bahaviour appears to be a new findings of this study. In previous studies. Indian criteria for assessment of social class, physical activity, alcohol intake and tobacco consumption have been validated ${ }^{[11,12]}$. In the present study, we report for the first time, the validity of Indian Rating Scale for assessment of type A behaviour in relation to social classes which may be used for assessment of behaviour at other centre's of India and abroad.

\section{SUBJECTS AND METHODS}

The details of subjects and methods have been described in the earlier papers ${ }^{[11,12]}$. The sampling frame consisted of 0.43 million population of Moradabad city based on census of India. We randomly selected 20 streets out of 180 urban streets after excluding 16 suburban streets from the total 196 streets. Each street had 6-12 blocks and each block containing 100-300 adults was considered as cluster. We selected 2 clusters from each street and from each one, 40-100 adults were randomly selected for this study. We contacted 2222 subjects aged 25 years and above of which $220(9 \%)$ failed to give cooperation. Of the remaining 2002 subjects, 1806 (904 men and 902 women) aged 2564 years inclusive, were invited for this study.

Detailed interviews were performed with the help of a pretested and validated questionnaire by a pre-trained psychologist to obtain information on age, past and family history of cardiovascular disease and socioeconomic status. Social classes were graded into 1-5 according to British Registrar General and other Indian studies based on attributes of education, occupation, housing conditions, ownership of consumer durables and per capita occupational and other incomes of the family and number of dependents as described earlier ${ }^{[11]}$. CAD was diagnosed by WHO criteria as described earlier ${ }^{[13]}$.

\section{Criteria for Assessment of Type A Behaviour}

Type A behaviour was assessed based on scores constructed on attributes of hostility, competitiveness, ambitiousness, pace or time urgency and aggressiveness without a wish to oppose and harm others. This modified version; the Indian rating scale is based on Likeret scale and other studie ${ }^{[6-8]}$ (Appendix). It is difficult to measure personality and behaviour in a community with a low rate of literacy ( $70 \%$ approximately) by a scale used in developed countries. Behaviour manifestations may also vary due to variation in socioeconomic status and cultural factors. Subjects were explained the meaning of each question if necessary in local language. Type A behaviour was considered in presence of a measurement score of 1520 and possible type A behaviour in presence of score 9 to 14 .

\section{Statistical Analysis}

A $P$ value of $<0.05$ was considered significant. The prevalence of type $\mathrm{A}$ behaviour was compared by using $\mathrm{Z}$ score test for proportions.

\section{RESULTS}

There were 1806 subjects aged 25-64 years including 804 men and 802 women. The prevalence of type A behaviour was $21.9 \%$ $(n=198)$ among males and $11.9 \%(n=108)$ among females. The overall prevalence of type A behaviour was $16.9 \%$. The prevalence was significantly higher in men than women. Table 1 shows The prevalence of possible type A behaviour were $10.5 \%$ in men and $6.8 \%$ in women and the overall prevalence was 8.77 . The combined prevalence of type A behaviour and possible type A behaviour was $25.6 \%$ in both sexes.

Table 2 shows the prevalence of type A behaviour in various social classes among male and female subjects. There was an increasing prevalence of type A behaviour with increase in social class in both male and female subjects. Majority of the type A behaviour subjects were in social class 1 and 2. Social class 3-5 had a very low prevalence of type A behaviour. Higher social class 1 and 2 were significantly associated with type A behaviour.

There were 100 men and 63 women with CAD. Type A behaviour was significantly associated with CAD in men $(68 \%$ vs $16.2 \%, p$

Table 1 Prevalence (\%) of type A behaviour in male and Female.

\begin{tabular}{|l|c|c|c|}
\hline & Male $(\boldsymbol{n}=\mathbf{9 0 4})$ & Female $(\boldsymbol{n}=\mathbf{9 0 2})$ & Total $(\boldsymbol{n}=\mathbf{1 8 0 6})$ \\
\hline Type A behaviour & $198(21.9)^{* *}$ & $108(11.9)$ & $306(16.9)$ \\
\hline Possible type A behaviour & $95(10.5)^{*}$ & $62(6.8)$ & $157(8.7)$ \\
\hline Total & $293(32.4)^{* *}$ & $170(18.8)$ & $463(25.6)$ \\
\hline
\end{tabular}

${ }^{*}=p<0.05,{ }^{* *}=p<0.01$ Values were obtained by Z score test for proportions by comparison of males and females.

Table 2 Prevalence of type A behaviour in relation to social classes.

\begin{tabular}{|l|c|c|c|c|c|c|}
\hline & \multicolumn{2}{|c|}{ Men } & \multicolumn{2}{c|}{ Women } & \multicolumn{2}{c|}{ All subjects } \\
\hline & Total & $\begin{array}{c}\text { Type A } \\
\mathbf{n}(\%)\end{array}$ & Total & $\begin{array}{c}\text { Type A } \\
\mathbf{n}(\%)\end{array}$ & Total & $\begin{array}{c}\text { Type A } \\
\mathbf{n}(\%)\end{array}$ \\
\hline Social class 1 & 300 & $122(40.6)$ & 290 & $80(27.6)^{* *}$ & 590 & $202(34.2)$ \\
\hline Social class 2 & 187 & $55(29.4)$ & 183 & $15(18.2)^{*}$ & 370 & $70(18.9)$ \\
\hline Social class 3 & 178 & $55(29.4)$ & 165 & $7(4.2)$ & 343 & $18(5.2)$ \\
\hline Social class 4 & 159 & $11(6.2)$ & 180 & $5(2.8)$ & 339 & $16(4.7)$ \\
\hline Social class 5 & 80 & $8(5.0)$ & 84 & $1(1.2)$ & 164 & $3(1.8)$ \\
\hline Total & 904 & $198(21.9)$ & 902 & $108(11.9)$ & 1806 & $463(25.6)$ \\
\hline
\end{tabular}

${ }^{*}=p<0.05,{ }^{* *}=p<0.01$ Values was obtained by comparison of social class 1 with social class 2 and of social class 1 and 2 with other social classes by $\mathrm{Z}$ score test for proportions.

Table 3 Prevalence of type A behaviour in relation to coronary artery disease.

\begin{tabular}{|l|l|l|l|l|l|l|}
\hline & \multicolumn{2}{|l|}{ Men $(\boldsymbol{n = 9 0 4 )}$} & \multicolumn{2}{l|}{ Women $(n=902)$} & \multicolumn{2}{l|}{ Total $(\boldsymbol{n}=\mathbf{1 8 0 6})$} \\
\hline & CAD & No CAD & CAD & No CAD & CAD & No CAD \\
\hline Subjects & 100 & 804 & 63 & 839 & 163 & 1643 \\
\hline $\begin{array}{l}\text { Type A } \\
\text { Behavior [n (\%)] }\end{array}$ & $68(68.0)$ & $130(16.2)$ & $32(50.7)$ & $76(9.0)$ & $100(61.3)$ & $206(12.5)$ \\
\hline
\end{tabular}

* $p<0.01$ by $\mathrm{Z}$ score test for proportions. 
$<0.001)$ and women $(50.7 \%$ vs $9.0 \%, p<0.001)$ including overall association in both men and women $(61.3 \%$ vs $12.5 \%, p<0.001)$ (Table 3).

\section{DISCUSSION}

The results of this study indicate that type A behavior has become a public health problem in India. The diagnosis of type A behavior can be accurately assessed by this questionnaire in the urban population of India and may be graded into type A behaviour or possible type A behaviour or no such behavior. The major attributes for the diagnosis of type A behavior are; hostility, aggressiveness, ambitiousness, competitiveness and pace or time urgency in an urban population of India," based on systematic theoretical analyses.

These assessments appear to be reasonably accurate and the Indian personality rating scale may be used without much problems in a semi-literate Indian urban population. However, the person administering the questionnaire should be able to explain the meaning of each question to subjects in local language. Our questionnaire has been modified from existing questionnaires used in United States and Europe for assessment of type A behaviour. This questionnaire is different from the existing ones because aggressiveness has been subgrouped into hostility characterized with strong reaction to a situation with a strong wish to harm and oppose others and aggressiveness without such attitude to others. We also categorized each attribute by giving scores of 0-4 depending upon the severity of attribute. The manifestations, of behaviour were classified into type A behaviour and possible type A behaviour as the population under study is under transition from poverty to affluence. It is possible that those who have possible type A behaviour now, may turn to have classical type A behaviour pattern during next few years of follow up, due to urbanization, occupational stress and further human development and affluence. The prevalence of type A behaviour was significantly greater among men than women. The overall prevalence of type A behaviour was $17 \%$. It is significantly lower than the rate $(50 \%)$ of type a behaviour in developed countries ${ }^{[6-10]}$. The prevalence of possible type A behaviour was $8.7 \%$. It seems that one forth of the urban adult population of India may have overall type A behaviour abnormality which is one half of that in developed countries (50\% vs 25.7\%).

There is uncertainty regarding the role of psycho-social factors and diet and lifestyle factors, in the pathogenesis of type A behavior, which may be due to lack of simple measures to assess these factors ${ }^{[14-16]}$. Self reported questionnaires are more popular for measuring the psychosocial factors and behaviour manifestations, however have low predictive value. Jenkins activity survey is used widely for assessment of type A behaviour, although its predictive value is lower than Likeret scale and structured interview devised by Friedman and Rosenman ${ }^{[6,7]}$.

Our study shows that social classes 1 and 2 were significantly associated with type A behaviour than social classes 3-5. It is possible that education, occupation and income that are greater among higher social classes may influence behaviour pattern. It is also observed from our study that type A behaviour was more prevalent among higher social classes 1-2 than social classes 3-5. However, it is not clear whether type A behaviour can play some role in improving socioeconomic status of Indian populations ${ }^{[16]}$, and whether increased intake of visible fat or sugar may be function of personality and behaviour $^{[17]}$. Figure 1.

There is uncertainty regarding the role of psycho-social factors in CAD which is mainly due to lack of simple measures to assess these factors. This study also shows that type A behaviour was significantly associated with CAD compared to those subjects without type A behaviour in both sexes $(61.3 \%$ vs $12.5 \%, p<0.001)$. The Western Collaborative Group Study began in 1960 in 3,524 subjects aged 39-59 years without CAD. After 8.5 years, it was observed that $13.2 \%$ of type A men had CAD compared with only $5.9 \%$ of type B men $^{[14]}$. The Framingham Heart Study measured type A behaviour by a self reported questionnaire (Framingham type A scale ${ }^{[15]}$. Type A behaviour was independent predictor of incidence of CAD in men and women aged 45-64 years. In both studies, this effect was independent of serum cholesterol, hypertension and smoking. It is clear from these data that association of type A behaviour with CAD is much greater among Indians than in developed countries. In a case control study from India, type A behaviour was significantly associated with $\mathrm{CAD}^{[16]}$. Figure 2

In a cross-sectional survey, 75 subjects, without any history of CAD underwent 64-slice computed tomography coronary angiography (CTCA) and were screened for traditional cardiac risk factors and for hostility, anger, and type D personality traits ${ }^{[18]}$. Among 48 patients (64\%) had evidence of coronary plaque, with mild $(31 \%)$, moderate $(33 \%)$, and severe $(35 \%)$ coronary stenosis. Male sex, hypertension, being overweight, and number of cardiovascular risk factors increased the likelihood of presence coronary artery plaques. There was a significant difference between coronary plaque presence vs. coronary plaque absence for anger (26 vs $\left.30 \%, \chi^{2}=6.82\right)$ and type D personality (23 vs $35 \% ; \chi^{2}=8.23$, $p=0.03)$, but not hostility $(p>0.05)$. Anger personality, and the type D subscale social inhibition, but not negative affectivity, were associated with an increased prevalence and severity of coronary plaque. Univariate analysis confirms anger (odds ratio, $\mathrm{OR}=1.38$, $95 \%$ confidence interval, $\mathrm{CI}=1.12-2.31)$, social inhibition $(\mathrm{OR}=$ $2.01,95 \% \mathrm{CI}=1.81-2.93)$, 'negative affectivity by social inhibition' $(\mathrm{OR}=1.24,95 \% \mathrm{CI}=1.12-2.14)$, and type $\mathrm{D}$ personality $(\mathrm{OR}=$ $1.9,95 \% \mathrm{CI}=1.11-2.03)$ as predictors of CAP presence. Moreover,

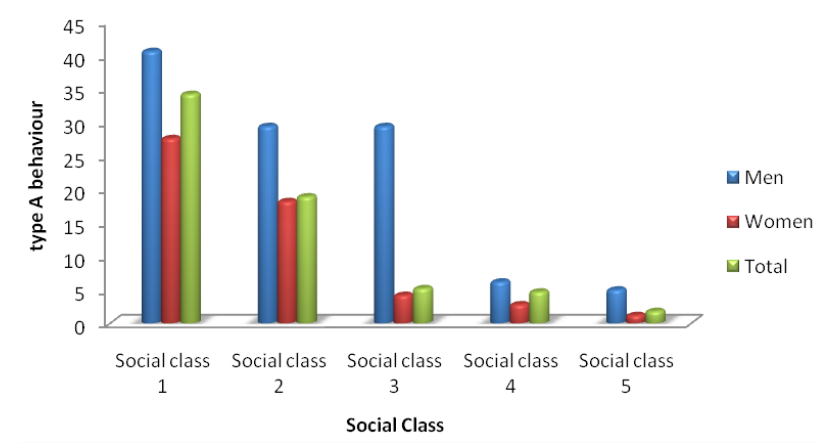

Figure 1 Prevalence of type A behaviour in relation to social classes among men and women.

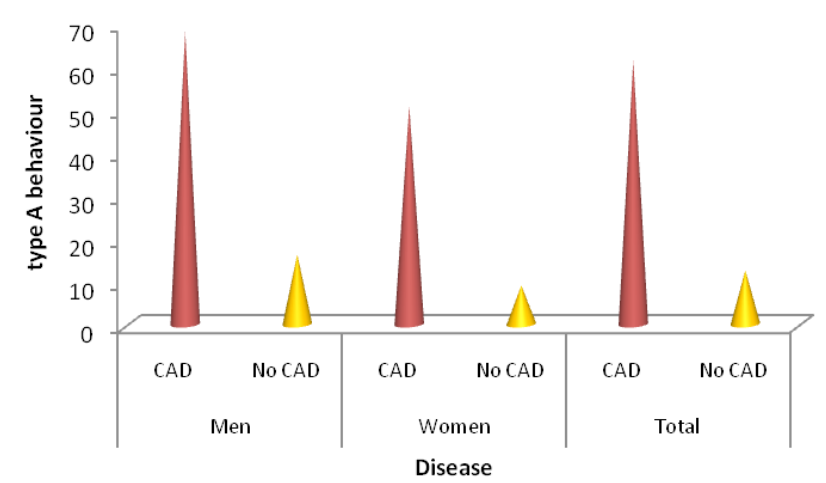

Figure 2 Prevalence of type A behaviour in relation to coronary artery disease among men and women. 
multivariate analysis suggests social inhibition as also a unique predictor of coronary plaque $(\mathrm{OR}=2.14,95 \% \mathrm{CI}=1.89-2.96)$ after adjustment for having cardiac risk factors as a covariate. The present data confirm the core role of traditional risk factors and suggest the primacy of social inhibition and anger personality traits in association with CAP presence and severity.

Personality traits may also be associated with major adverse coronary events (MACE) in patients with CAD $)^{[19]}$. However, the link between personality traits and intravascular morphology in CAD patients is poorly understood. Recent study investigated the relationship between personality traits, specifically Type A behavior pattern and Type D personality, and plaque vulnerability ${ }^{[19]}$. Type D personality was independently associated with lipid plaque, thin cap fibro-atheroma (TCFA), and fibrous cap thickness. More specifically, negative affectivity of Type D was related to lipid plaque, TCFA and fibrous cap thickness, and social inhibition was associated with plaque rupture. The results showed that type D personality was associated with plaque vulnerability, independent of clinical factors. Measurement of negative affectivity and social inhibition will increase our understanding of the progressive phase of the plaque vulnerability, which can contribute to the early identification of high risk patients and reduce the incidence of $\mathrm{MACE}^{[19]}$.

In a cohort study among 1,069 subjects, aged 64.81 years from the Swedish Twin Registry, the subjects were followed consecutively for 23 years $^{[20]}$. The diagnosis of type A behavior pattern was based on; ambition, stress, hard-driving, neuroticism, cynicism, and paranoia and presence CVD was self-reported and dementia was diagnosed adhering to DSMIII- $R$ or $D S M-I V$ criteria. The results revealed that some features of type A behavior pattern may confer an increased risk for dementia in those with CVD compared to subjects without CVD. It was suggested that evaluation of the risk of dementia may be considered among subjects with CVD and personality traits should be taken into consideration. In a clinical study from China, among 220 patients with stable angina or non-ST segment elevation acute coronary syndrome (NSTE-ACS) treated with PCI completed type A behavioral questionnaire, type $\mathrm{D}$ personality questionnaire ${ }^{[21]}$. The patients that had intervention were more likely to have type A and type D personality which was associated with myocardial injury. The frequency of obvious anxiety, depression emotion, and lower level of mental health, were more common among these patients and were related to personality and coping style. Type $\mathrm{D}$ personality was an independent predictor of adverse events. These findings indicate that chronic anxiety disorders are rapidly emerging in developing countries with increase in affluence. Functional MRI studies have demonstrated that anxiety disorders such as type A behavior and depression may be associated with smaller brain area of amygdala which is responsible for aggressive behavior, fear and grief and predisposes athero-thrombosis ${ }^{[22]}$. A recent study has also revealed that acute myocardial infarction can cause neuro-inflammation resulting in to damaging effect of certain areas such as amygdala of brain which may result in to aggression or type A behavior in patients with $\mathrm{CAD}^{[23]}$.

In brief, the findings of this study indicate that the prevalence of type A behaviour was approximately one half, in this part of urban India, compared to developed countries and it is more common among higher social classes. Assessment of type A behaviour based on scores constructed by different attributes appear to be accurate and the Indian type A behaviour rating scale (Appendix) may be successfully used to assess behaviour pattern in other developing populations by other investigators. Type A behaviour assessed by this rating scale was significantly associated with $\mathrm{CAD}$.

\section{Conflict of interest has not been declared by the authors.}

Acknowledgements: Financial support was provided by Sandoz (Novartis) foundation of Gerontologic Research, Australia, Halberg Hospital and Research Institute and Centre of Nutrition Research, Civil Lines, Moradabad, India

\section{REFERENCES}

1. WHO Study Group. Diet, Nutrition and Prevention of Chronic Diseases. WHO, Geneva, 1990.

2. Indian Consensus Group. Indian consensus for prevention of hypertension and coronary artery disease. A joint scientific statement of Indian Society of Hypertension and International College of Nutrition. New Delhi, 1995. J Nutr Environ Med 1996; 6: 309-318.

3. Singh RB, Niaz MA. Coronary risk factors in Indians. Lancel 1995; 346: 778-779.

4. Enas EA, Yusuf S, Sharma S. Coronary artery disease in South Asians. Indian Heart J 1998; 50: 105-113.

5. Case RB, Heller SS, Case NB, Moss AJ and the multi-centre PostInfarction Research Group. Type A behaviour and survival after acute myocardial infarction. N Engl J Med 1985; 312: 737-42.

6. Friedman M, Rosenman R. Association of specific overt behaviour pattern with blood and cardiovascular findings JAMA 1959; 12: 1286-1296.

7. Johnston DW. The current status of the coronary-prone behaviour pattern. J Roy Soc Med 1993; 86: 406-409.

8. Whiteman MC, Fowkers FGR and Deary IJ. Hostility and the heart. BMJ 1997; 315: 379-380.

9. Kawachi I, Sparrow D, Vokonas PS, Weiss ST. Symptoms of anxiety and risk of coronary heart disease: the normative aging study. Circulation 1996; 5: 2225-2229.

10. Booth-Kewley S, Friedman HS. Psychological predictors of heart disease: a quantitative review. Psychol Bull 1987; 101: 303-362.

11. Singh RB, Ghosh S, Niaz MA, Rastogi V. Validation of physical activity and socioeconomic status questionnaire in relation to food intakes for the five city study and a proposed classification for Indians. J Asso Phys India 1997; 45: 603-607.

12. Singh RB, Ghosh S, Niaz MA, Rastogi V, Wander GS. Validation of tobacco and alcohol intake questionnaire in relation to food intakes for the five city study and a proposed classification for Indians. $J$ Asso Phys India 1998; 46: 587-591.

13. Singh RB, Sharma JP, Rastogi V, Raghuvanshi RS, Moshiri M, Verma SP and Janus ED. Prevalence of coronary artery disease and coronary risk factors in rural and urban populations of north India. Eur Heart J 1997; 18: 1728-1735.

14. Rosenman RH, Brand RJ, Jenkins CD, Friedman M, Straus R, Wurm M. Coronary heart disease in Western Collaborative Group Study: Final follow up experience 8.5 years. JAMA 1975; 233: 872877.

15. Haynes SG, Feinleib M, Kannel WB. The relationship of psychological factors to coronary heart disease in the Framingham study III. Eight year incidence of coronary artery disease. Am J Epidemiol 1980; 111: 37-38.

16. Joshi VD. Type A Behaviour and Risk of Coronary Heart Disease. Thesis for Doctor of Medicine, Banaras Hindu University, Varanasi, 1973.

17. Singh R. Study of Nutrition, Anxiety, Stress and Behaviour in Relation to Cardiovascular Risk Factors in the Elderly Urban Population of Moradabad. Thesis submitted and PhD awarded by Ruhelkhand University, Bareilly, India 1998.

18. Compare A, Mommersteeg PM, Faletra F, Grossi E, Pasotti E, Moccetti T, Auricchio A. Personality traits, cardiac risk factors, and their association with presence and severity of coronary artery plaque in people with no history of cardiovascular disease. $J$ Cardiovasc Med (Hagerstown). 2014 May; 15(5): 423-30. [DOI: 
10.2459/JCM.0b013e328365cd8c]

19. Lin P, Li L, Wang Y, Zhao Z, Liu G, Chen W, Tao H, Gao X. Type D personality, but not Type A behavior pattern, is associated with coronary plaque vulnerability. Psychol Health Med. 2017; Jun 21: 1-8. doi: 10.1080/13548506.2017.1344254. [Epub ahead of print]

20. Bokenberger K, Pedersen NL, Gatz M, Dahl AK. The type A behavior pattern and cardiovascular disease as predictors of dementia. Health Psychology : official journal of the Division of Health Psychology. American Psychological Association. 2014; 33(12): 1593-1601. [DOI: 10.1037/hea0000028]

21. Du J, Zhang D, Yin Y, Zhang X, Li J, Liu D, Pan F, Chen W. The personality and psychological stress predict major adverse cardiovascular events in patients with coronary heart disease after percutaneous coronary intervention for five years. Wang. H, ed. Medicine. 2016; 95(15): e3364. [DOI: 10.1097/MD. 0000000000003364]

22. Singh RB, Cornelissen G, shastun S, Fedacko J. Atherosclerosis? A disease of the brain. World Heart J 2017; 9: 99-106.

23. Thackeray JT, Hupe HC, Wang Y, Bankstah JP, Berding G. Ross TL, Bauersachs J, Kai C. Wollert KC, Frank M. Bengel FM. Myocardial inflammation predicts remodeling and neuro-inflammation after myocardial infarction. J Am Coll Cardiol 2018; 71: 263-275

Peer Reviewer: AKM Monwarul Islam 


\section{APPENDIX}

Indian rating scale for type A behaviour Behaviour manifestations studied for type A behaviour

a. Hostility (wish to oppose and harm others)

b. Aggressiveness without a wish to oppose and harm others.

c. Competitiveness.

d. Ambitiousness.

e. Pace or time urgency.

Scores constructed on each of these attributes $(0-4), 0=$ none

(a) Hostility

4 , if aggressive behaviour with a strong wish to oppose and harm others, especially unexpressed anger.

3 , if characteristic facial net exhibiting aggression by constriction of eye and jaw muscles or characteristic L4 like drawing back of corners of lips exposing the teeth.

2 , if use of clinched fist on table, pounding or forceful closing of hands and fingers or exhibit initiation and rage when asked about part of event which made him angered.

1, Unable to tolerate when kept waiting and express general distrust on others and can not work in team, explosive speech and over critical.

(b) Aggressiveness :

4, if strongly react to a situation with above characteristics without a wish to oppose and harm others but the agitation continues for several days.

3 , if aggressiveness disappears after few hours but can not work in team.

2 , if aggressiveness followed by feeling of guilt.

1 , if aggressive for moments followed by calm down.

(c) Competitiveness:

4,game with an aim to win even with young children.

3 , Irritate on kept waiting and impatient

2 , if become tense to achieve better than others in his main occupation.

1 , if irritate on not doing better than others in routine work.

(d) Ambitiousness:

4 , if strongly desire to achieve highest in the field.

3 , if self awareness of type A behaviour.

2 , if polyphasic activity eg multiple works at a times or preoccupied by multiple thoughts.

1 , if difficulty in sitting and doing nothing and subject habitually substitutes numerals for metaphors in his speech.

(e) Pace or time urgency:

4, if characteristic facial tantriness expressing tension or rapid horizontal eye ball movements during ordinary conversation or rapid eye blinking over 40 blinks/minute.

3 , if knee jiggling or rapid vigorous taping of fingers, or rapid body movements.

2 , if lip clicking during ordinary speaking or rapid tic like eyebrow lifting or tense posture.

1 , if walk and eat faster or spouse usually tell to slow down and subject make all efforts to be in time or multiple works at a time.

Rating of type A behaviour by scores:

Type A behaviour

$15-20$

Type A behavior; within normal limits
$9-14$

$1-8$ 